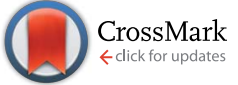

Cite this: Chem. Sci., 2016, 7, 5470

\title{
Crystal engineering of a family of hybrid ultramicroporous materials based upon interpenetration and dichromate linkers $\dagger$
}

\begin{abstract}
Hayley S. Scott, $\$^{\mathrm{a}}$ Naoki Ogiwara, $\dot{t}^{\mathrm{b}}$ Kai-Jie Chen, ${ }^{\mathrm{a}}$ David G. Madden, ${ }^{\mathrm{a}}$ Tony Pham, ${ }^{\mathrm{c}}$ Katherine Forrest, ${ }^{\mathrm{C}}$ Brian Space, ${ }^{\mathrm{C}}$ Satoshi Horike, ${ }^{\mathrm{b}}$ John J. Perry IV, ${ }^{a}$ Susumu Kitagawa ${ }^{\star b d}$ and Michael J. Zaworotko*a

A new family of 2 -fold interpenetrated primitive cubic (pcu) networks of formula $\left[\mathrm{M}(\mathrm{L})_{2}\left(\mathrm{Cr}_{2} \mathrm{O}_{7}\right)\right]_{n}\left(\mathrm{M}=\mathrm{Co}^{2+}\right.$, $\mathrm{Ni}^{2+}, \mathrm{Cu}^{2+}$ and $\mathrm{Zn}^{2+} ; \mathrm{L}=4,4^{\prime}$-azopyridine), DICRO-3-M-i, has been synthesised and their structures, permanent porosity and gas sorption properties were comprehensively characterised. Molecular simulations indicate that $\mathrm{CO}_{2}$ molecules occupy both of the two distinct ultramicropores that run through this isostructural series. The orientation of the $\mathrm{Cr}_{2} \mathrm{O}_{7}{ }^{2-}$ pillars is thought to contribute to high isosteric enthalpy of adsorption $\left(Q_{\mathrm{st}}\right)$ towards $\mathrm{CO}_{2}$ and temperature programmed desorption experiments reveal that DICRO-3-Ni-i selectively adsorbs $\mathrm{CO}_{2}$ from gas mixtures that simulate flue gas. Performance in this context is among the highest for physisorbents measured to date and these materials are readily regenerated at $50{ }^{\circ} \mathrm{C}$.
\end{abstract}

Received 30th March 2016

Accepted 10th May 2016

DOI: $10.1039 / \mathrm{c} 6 \mathrm{sc} 01385 f$

www.rsc.org/chemicalscience

certain sorbates and stability towards humidity: incorporation of strong electrostatics thanks to the use of inorganic linker anions that expose electronegative atoms to pore walls; the use of short organic linker ligands or interpenetration to generate ultramicropores $(<0.7 \mathrm{~nm})$. The resulting materials, Hybrid Ultramicroporous Materials, HUMs, ${ }^{6,7}$ can exhibit strong and selective adsorption sites for important sorbates such as $\mathrm{CO}_{2}$. Indeed, HUMs have set a series of benchmarks for selectivity $(S)$ to $\mathrm{CO}_{2}$ over competing less polarisable gases like $\mathrm{N}_{2}\left(S_{\mathrm{CN}}\right)^{7-9}$ and vapours such as $\mathrm{H}_{2} \mathrm{O}\left(S_{\mathrm{CW}}\right){ }^{6 \boldsymbol{b}}$

An important feature of HUMs is that they are inherently modular, which makes them amenable to fine-tuning through substitution of one or more of their components. To date, we have developed two related platforms of HUMs using the same simple design strategy, i.e. the use of inorganic linker anions to

We have recently undertaken systematic examination of an underexplored subclass of porous materials that combines two key features, which together can enhance selectivity towards

${ }^{a}$ Bernal Institute, Department of Chemical and Environmental Science, University of Limerick, Republic of Ireland. E-mail: xtal@ul.ie

${ }^{b}$ Department of Synthetic Chemistry and Biological Chemistry, Kyoto University, Katsura, Nishikyo-ku, Kyoto, 615-8510, Japan

'Department of Chemistry, University of South Florida, 4202 East Fowler Avenue, Tampa, Florida 33620, USA

${ }^{d}$ Institute for Integrated Cell-Material Sciences (iCeMS), Kyoto University, Yoshida, Sakyo-ku, Kyoto, 606-8501, Japan

$\dagger$ Electronic supplementary information (ESI) available: PXRD, TGA, FT-IR, molecular simulations, structural and sorption data. CCDC 1468766-1468769. For ESI and crystallographic data in CIF or other electronic format see DOI: 10.1039/c6sc01385f

\$ H. S. S. and N. O. contributed equally.
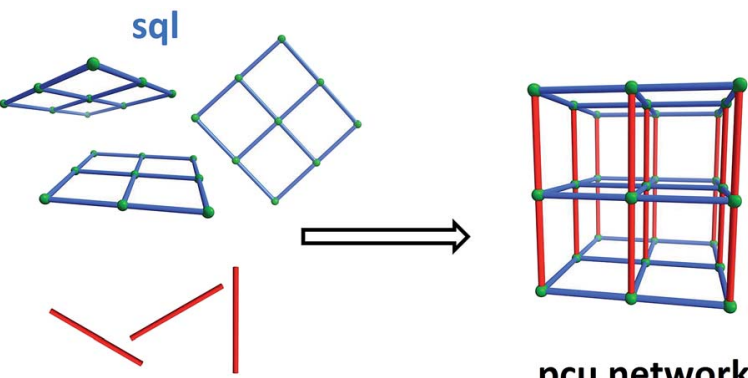

pcu network

\section{Inorganic Pillar}

Scheme 1 Self-assembly of pillared pcu topology networks from sql networks cross-linked by linear inorganic anions that serve as pillars. 
pillar square grid lattice (sql) coordination networks (Scheme 1). The resulting networks are based upon the following linker anions: hexafluorometallate anions $\left(e . g\right.$. $\mathrm{SiF}_{6}{ }^{2-}$, SIFSIX) that pillar in linear fashion to generate primitive cubic (pcu) networks $^{6 \boldsymbol{b}, 7}$ (this platform also includes analogues which exhibit supermicropores, i.e. $>0.7$ but $<2 \mathrm{~nm}){ }^{8}$ mmo topology networks that incorporate angular pillars which enable self-penetration of the sql nets $\left(\mathrm{CrO}_{4}{ }^{2-}, \mathrm{MoO}_{4}{ }^{2-}, \mathrm{WO}_{4}{ }^{2-}\right) .{ }^{9}$ We have also reported the first porous pcu network sustained by $\mathrm{Cr}_{2} \mathrm{O}_{7}{ }^{2-}$ (DICRO) linear linkers, DICRO-2-Ni-i ${ }^{6 \boldsymbol{a}}$ ( $2=1,2$-bis(4-pyridyl) acetylene), but a hitherto unprecedented angled mode of interpenetration mitigated against strong gas sorption performance towards $\mathrm{CO}_{2}{ }^{6 \boldsymbol{a}}$ The first two platforms seem to validate the effect upon gas sorption performance when combining ultramicropores and high electrostatics in the same material. Specifically, their modular nature enabled systematic finetuning of both pore size and pore chemistry to optimise physisorption performance. These observations prompted us to study other families of HUMs.

Two crystal engineering approaches exist for the formation of networks that exhibit ultramicropores: incorporation of short linkers $(<0.7 \mathrm{~nm})$; interpenetration of two or more networks with relatively large cavities that afford much reduced pore size following interpenetration. Interpenetration was initially thought of as a hindrance to gas sorption applications. ${ }^{\mathbf{1 0}}$ Indeed, the prototypal pcu net that is sustained by DICRO pillars, DICRO-1-M-i, $1=4,4^{\prime}$-bipyridine, $\left(\mathbf{M}^{2+}=\mathrm{Fe},{ }^{11} \mathrm{Co},{ }^{12} \mathrm{Ni}\right.$ (ref. 13) and $\mathrm{Cu} ;{ }^{13} \mathbf{i}=$ interpenetrated) eschews porosity because of 2-fold interpenetration. Nevertheless, it is becoming apparent that interpenetration, a well-recognised phenomenon, ${ }^{4 c}$ can be an effective tool to generate ultramicroporous materials that exhibit high isosteric enthalpy of adsorption $\left(Q_{\mathrm{st}}\right)$ and high selectivity for polarisable gases. ${ }^{7 b}$

We report herein a family of 2-fold interpenetrated HUMs based upon DICRO pillars: $\left[\mathrm{M}\left(4,4^{\prime} \text {-azopyridine }\right)_{2}\left(\mathrm{Cr}_{2} \mathrm{O}_{7}\right)\right]_{n}$, DICRO-3-M-i, $\left(3=4,4^{\prime}\right.$-azopyridine; $\left.\mathbf{M}=\mathrm{Co}^{2+}, \mathrm{Ni}^{2+}, \mathrm{Cu}^{2+}, \mathrm{Zn}^{2+}\right)$. DICRO-3-M-i form pcu topology nets which exhibit offset interpenetration and their pore walls are lined by inorganic moieties, unlike DICRO-2-Ni-i. ${ }^{6 \boldsymbol{a}}$ The DICRO-3-M-i family was characterised by single-crystal and powder X-ray diffraction, thermogravimetric analysis (TGA), FT-IR spectroscopy (FTIR), single component gas sorption measurements $\left(\mathrm{CO}_{2}\right.$ and $\left.\mathrm{N}_{2}\right)$, molecular simulations of $\mathrm{CO}_{2}$ adsorption, and temperature programmed desorption (TPD) experiments coupled with TGA/ mass spectrometry (MS). We evaluated the performance of DICRO-3-Ni-i in the context of direct capture of $\mathrm{CO}_{2}$ from air and five other gas mixtures including simulated flue gas. The stability of DICRO-3-Ni-i to atmospheric water vapour was studied via standard accelerated stability tests ${ }^{6 \boldsymbol{b}}$ that simulate long-term storage or "shelf-life".

\section{Results and discussion}

\section{Syntheses and characterisation}

Single-crystals of DICRO-3-M-i $\left(\mathbf{M}=\mathrm{Ni}^{2+}, \mathrm{Cu}^{2+}, \mathrm{Zn}^{2+}\right)$ were prepared via slow diffusion of aqueous $\mathrm{K}_{2} \mathrm{Cr}_{2} \mathrm{O}_{7} / \mathrm{M}\left(\mathrm{NO}_{3}\right)_{2}$ into MeCN solutions of ligand 3 at room temperature. Yellow block- shaped crystals were obtained after one week. Single-crystals of DICRO-3-Co-i were synthesised by heating a sealed vial of reagents dissolved in $\mathrm{H}_{2} \mathrm{O}$ to $120^{\circ} \mathrm{C}$ for $48 \mathrm{~h}$, followed by cooling to $30{ }^{\circ} \mathrm{C}$ over $6 \mathrm{~h}$. DICRO-3-Co-i formed as small, block-shaped, dark red coloured crystals that were weakly diffracting. As such, the crystallographic data for DICRO-3-Co-i is of low quality; however, the space group and crystal packing matches the other three compounds in the series. DICRO-3-M-i were also synthesised via direct mixing of reagents to afford powder samples suitable for use in gas sorption studies. All four compounds were found to be stable after one week of exposure to ambient conditions. PXRD data are provided in the ESI; Fig. S1-S4. $\dagger$ Thermogravimetric analyses reveal that all four compounds exhibit thermal stability to a least $200{ }^{\circ} \mathrm{C}$ (Fig. S5 $\dagger$ ). Infrared spectra are presented in Fig. S6. $\dagger$

\section{Structural analysis}

Single-crystal diffraction analysis of DICRO-3-M-i revealed that they are isostructural, crystallising in the triclinic space group $P \overline{1}$. The hexacoordinate metal centres serve as six-connected (6c) nodes in pcu topology networks. ${ }^{14}$ Four pyridyl groups from four different linker ligands comprise the equatorial plane (Fig. 1) which propagates to the expected sql network. Average $\mathbf{M}^{2+}-\mathrm{N}$ bond lengths, $2.15 \AA$ (Co), $2.08 \AA$ (Ni), $2.02 \AA$ (Cu) and $2.16 \AA$ (Zn), are consistent with the DICRO-1-M-i family according to data archived in the Cambridge Structural Database (CSD). ${ }^{15}$ The axial positions of the $\mathbf{M}^{2+}$ centres coordinate to oxygen atoms from $\mathrm{Cr}_{2} \mathrm{O}_{7}{ }^{2-}$ anions, which pillar the sql nets to afford the observed pcu networks. A survey of the CSD revealed that, excluding polyoxometalates, there are only 23 structures of transition metals coordinated to $\mathrm{Cr}_{2} \mathrm{O}_{7}{ }^{2-}$ anions. Of these, 18 structures involve $\mathrm{Cr}_{2} \mathrm{O}_{7}{ }^{2-}$ ligands that are bridging. $\mathbf{M}^{2+}-\mathrm{O}$ distances of 2.012(7) $\AA$ (Co), 2.047(3) $\AA$ (Ni), 2.274(4) $\AA$ (Cu) and 2.088(2) $\AA$ ( $\mathbf{Z n})$ are within expected ranges. The $\mathrm{Cu}-\mathrm{O}$ bonds in DICRO-3-Cu-i are elongated because of Jahn-Teller distortion. Cr ions exhibit tetrahedral geometry with average $\mathrm{O}-\mathrm{Cr}-\mathrm{O}$ angles of $109.65(4)^{\circ}$ (Co), 109.20(17) $)^{\circ}$ (Ni), 108.2(2) $)^{\circ}(\mathbf{C u})$ and $109.24(12)^{\circ}(\mathbf{Z n})$. In each compound, the terminal $\mathrm{Cr}-\mathrm{O}$ bond distances are shorter than the bridging $\mathrm{Cr}-$

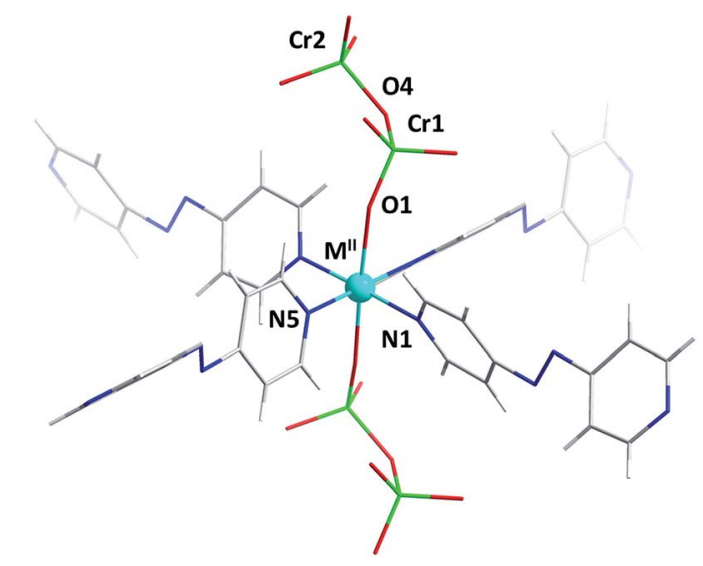

Fig. 1 Coordination environment in the DICRO-3-M-i family. 
O distances, which is consistent with previously reported structures. ${ }^{11-13}$ The $\mathrm{Cr}(1)-\mathrm{O}(4)-\mathrm{Cr}(2)$ angles for DICRO-3-Ni-i, DICRO-3-Cu-i and DICRO-3-Zn-i range between 126.0(2)$127.3(3)^{\circ}$ but are more obtuse in DICRO-3-Co-i $\left(135.6(5)^{\circ}\right)$. Crystallographic details and selected bond lengths and angles are summarised in Tables 1 and $\mathrm{S} 1-\mathrm{S} 2 . \dagger$

The pcu networks feature rhombohedral cavities with dimensions of $c a .8 \times 13 \times 13 \AA$ (defined by $\mathrm{M} \cdots \mathrm{M}$ distances) that enable 2 -fold interpenetration in which the node of the second net is "offset" from the cavity of the first net (Fig. 2). This mode of interpenetration is commonly encountered in 2-fold interpenetrated pcu networks and is also seen in DICRO-1-Mi. ${ }^{11-13}$ The offset arrangement could be an artifact of $\mathrm{C}-\mathrm{H} \cdots \mathrm{O}$ interactions between pyridyl groups of one network and the $\mathrm{Cr}_{2} \mathrm{O}_{7}{ }^{2-}$ pillars of the adjacent network (Fig. S7-S8 $\dagger$ ).

Notably, offset interpenetration results in four crystallographically distinct channels running through the structure parallel to the $a$-axis. However, only two of these channels are large enough to accommodate even small guest molecules. Channels A and B (Fig. 2) exhibit pore diameters of 4.4-5.8 and 3.0-3.4 $\AA$, respectively, based upon the closest $\mathrm{O} \cdots \mathrm{O}$ and $\mathrm{C} \cdots \mathrm{C}$ distances for channels $\mathrm{A}$ and $\mathrm{B}$ respectively (minus van der Waals radii). The larger of the two channels is lined by terminal O-atoms from $\mathrm{Cr}_{2} \mathrm{O}_{7}{ }^{2-}$ pillars (O6) that orient towards the inside of the channel. For channel B, the terminal O-atom (O3) does not protrude into the cavity. The location of accessible $\mathrm{O}$ atoms from the dichromate inorganic pillars in these networks could be of significance with respect to gas sorption, as discussed earlier and below. Channel A has features that resemble a member of the MFSIX platform, $\left[\mathrm{Cu}(\mathrm{L})_{2}\left(\mathrm{SiF}_{6}\right)\right](\mathrm{L}=1,2$-bis(4pyridyl)acetylene), SIFSIX-2-Cu-i, ${ }^{7 \boldsymbol{b}}$ which displays centred, 2fold interpenetration and one type of channel. This is because the staggered disposition of the interpenetrated nets results in electronegative atoms (O-atoms in the case of DICRO, F-atoms in the case of SIFSIX) protruding into the channel walls in such a manner that the electronegative atoms are 7-8 $\AA$ apart. These features are discussed in relation to gas sorption and isosteric enthalpy of adsorption in the next section.

\section{Gas sorption analyses}

Single component $\mathrm{CO}_{2}$ and $\mathrm{N}_{2}$ sorption measurements were performed on DICRO-3-Ni-i, DICRO-3-Co-i and DICRO-3-Cu-i to determine gas uptake, ideal selectivity and isosteric enthalpy of

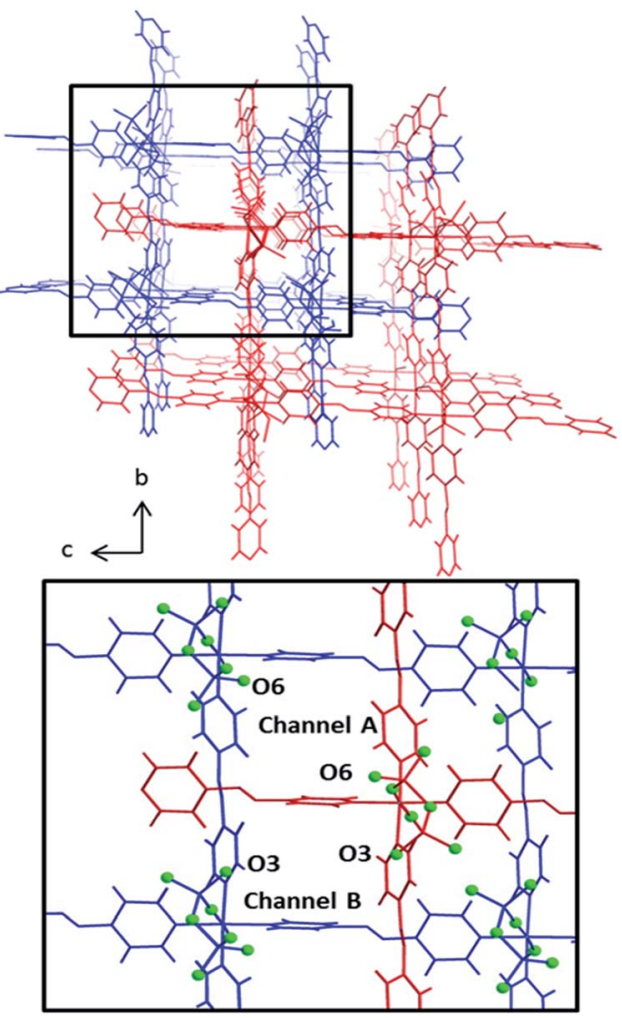

Fig. 2 Top: Packing of pcu nets in DICRO-3-M-i, frameworks shown in red and blue, viewed down the a-axis. Bottom: Inset of top figure. Channel A exhibits a terminal O-atom (O6) protruding into the channel. Channel B has an O-atom (O3) lining the channel wall. Oatoms are coloured light-green and presented in ball-and-stick mode.

adsorption $\left(Q_{\text {st }}\right)$. PXRD patterns reveal that DICRO-3-Zn-i loses crystallinity with loss of solvent and it also exhibits low uptake of $\mathrm{N}_{2}$ at $77 \mathrm{~K}$ and $\mathrm{CO}_{2}$ at $195 \mathrm{~K}$ (Fig. S9 and S10†). DICRO-3-Zn-i was therefore not studied further in terms of gas sorption. The permanent porosities of DICRO-3-Co-i, DICRO-3-Ni-i and DICRO-3-Cu-i were established by $\mathrm{N}_{2}$ isotherms at $77 \mathrm{~K}$ (Fig. S9†). The apparent BET surface area was calculated to be 142, 388 and $325 \mathrm{~m}^{2} \mathrm{~g}^{-1}$ for DICRO-3-Co-i, DICRO-3-Ni-i and DICRO-3-Cu-i, respectively. Pore volumes of 0.052, 0.143 and $0.122 \mathrm{~cm}^{3} \mathrm{~g}^{-1}$ for DICRO-3-Co-i, DICRO-3-Ni-i, and DICRO-3Cu-i were calculated by assuming liquid filling of $\mathrm{N}_{2}$ at the $P / P_{0}$ $=0.95$. These values are similar to those calculated from the

Table 1 Selected bond lengths and angles for DICRO-3-M-i

\begin{tabular}{|c|c|c|c|c|}
\hline $\mathbf{M}^{\mathrm{II}}-\mathrm{N} 1 \AA$ & $2.162(7)$ & $2.108(3)$ & $2.036(5)$ & $2.160(3)$ \\
\hline $\mathbf{M}^{\mathrm{II}}-\mathrm{N} 5 \AA$ & $2.142(9)$ & $2.069(4)$ & $2.020(5)$ & $2.161(2)$ \\
\hline $\mathrm{Cr} 1-\mathrm{O} 4-\mathrm{Cr} 2^{\circ}$ & $135.6(5)$ & $125.9(2)$ & $127.3(3)$ & $126.06(16)$ \\
\hline $\mathbf{M}^{\mathrm{II}}-\mathrm{O} 1-\mathrm{Cr} 1$ & $154.9(5)$ & $158.7(2)$ & $167.0(2)$ & $163.25(14)$ \\
\hline Torsion angle of $3\left(^{\circ}\right)$ & $61.7^{a} 57.2^{b}$ & $105.2,^{a} 94.8^{b}$ & $62.3,^{a} 72.3^{b}$ & $77.3,^{a} 64.5^{b}$ \\
\hline
\end{tabular}

${ }^{a}$ Torsion angle of $\mathrm{C} 2 \mathrm{C} 3 \mathrm{C} 6 \mathrm{C} 7 .{ }^{b}$ Torsion angle of C12C13C16C17. 
crystallographic data using PLATON ${ }^{16}$ for DICRO-3-Ni-i and DICRO-3-Cu-i ( 0.158 and $0.151 \mathrm{~cm}^{3} \mathrm{~g}^{-1}$, respectively). The lower uptake exhibited by DICRO-3-Co-i could be attributed to partial collapse of the network following activation.

$\mathrm{CO}_{2}$ and $\mathrm{N}_{2}$ sorption isotherms at 273,283 and $293 \mathrm{~K}$ were collected for DICRO-3-Co-i, DICRO-3-Ni-i and DICRO-3-Cu-i. $293 \mathrm{~K}$ isotherms for both gases are presented in Fig. 3 (top), while 273, 283 and $293 \mathrm{~K}$ isotherms are given in the ESI (Fig. S11-S13†). A summary of gas sorption data is also provided in Table 2. DICRO-3-Co-i and DICRO-3-Ni-i both exhibit type I isotherms for $\mathrm{CO}_{2}$ sorption whereas DICRO-3-Cu-i has a distinct step and hysteresis. The step observed in the $\mathrm{CO}_{2}$ adsorption isotherms for DICRO-3-Cu-i varies with temperature, occurring at higher partial pressures and becoming more gradual at higher temperature. The stepped nature of the isotherm observed for DICRO-3-Cu-i may be due to either of two structural changes: translation of independent networks with respect to one another upon increased $\mathrm{CO}_{2}$ sorption, a phenomenon that has been reported previously for similar systems; ${ }^{17}$ flexible networks switching between a narrow pore (NP) and a large pore (LP) form, which has also been observed in pcu networks. ${ }^{17 b, 18}$ Since, stepped isotherms were not observed for the $\mathbf{C o}$, Ni and $\mathbf{Z n}$ analogues it seems unlikely that translation of independent networks is the origin for the stepped behaviour seen in DICRO-
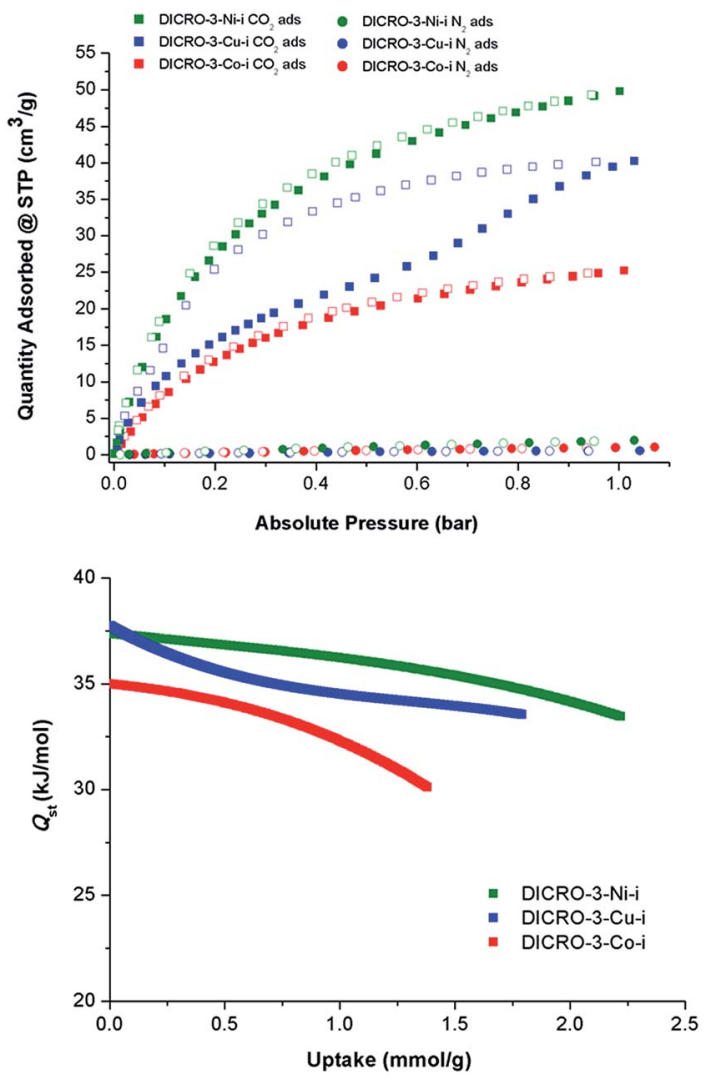

Fig. 3 Top: Single component gas sorption isotherms for DICRO-3$\mathrm{M}$-i at $293 \mathrm{~K}(\mathrm{Co}=\mathrm{red}, \mathrm{Ni}=$ green, $\mathrm{Cu}=$ blue $)$. Solid symbols signify adsorption while empty symbols represent desorption measurements. Bottom: Isosteric enthalpy of adsorption $\left(Q_{\mathrm{st}}\right)$ of DICRO-3-M-i compounds towards $\mathrm{CO}_{2}$.
3-Cu-i. $\mathrm{Cu}^{2+}$ exhibits Jahn-Teller distortion, which is known to be temperature dependent (the distortion is less pronounced at higher temperatures). The stepped nature of the isotherm could therefore be a consequence of the effect of Jahn-Teller distortion upon the coordination sphere, which would in turn affect the pore size and shape. To verify this hypothesis, PXRD experiments were conducted on 'as-synthesised' powder at ambient pressure, at reduced pressure and again after the powder was cycled back to ambient pressure. A phase change is apparent from the PXRD patterns (Fig. S14 $\dagger$ ) but attempts to collect diffraction data on single-crystals of DICRO-3-Cu-i at reduced pressure were unsuccessful.

Selectivity for $\mathrm{CO}_{2}$ over $\mathrm{N}_{2}\left(S_{\mathrm{CN}}\right)$ for DICRO-3-Co-i, DICRO-3Ni-i and DICRO-3-Cu-i was calculated from the uptakes of $\mathrm{CO}_{2}$ at 0.15 bar and $\mathrm{N}_{2}$ at 0.85 bar at $293 \mathrm{~K}$ to be $70.2,79.3$ and 145.9, respectively. The relatively high $S_{\mathrm{CN}}$ for DICRO-3-Cu-i is partly a result of its very low $\mathrm{N}_{2}$ uptake at $293 \mathrm{~K}$. Such $S_{\mathrm{CN}}$ values are comparable to porous MOMs containing amino-functional groups and open-metal sites, which are absent herein. ${ }^{19}$

$\mathrm{CO}_{2}$ isotherms measured at 273,283 and $293 \mathrm{~K}$ were fitted using the virial equation (Fig. S15, S17, S19†), and the isosteric enthalpy of adsorption $\left(Q_{\mathrm{st}}\right)$ was calculated using the Clausius-Clapeyron equation. ${ }^{20} Q_{\text {st }}$ values at low loading for DICRO-3-Co-i, DICRO-3-Ni-i and DICRO-3-Cu-i are 35, 37 and $37 \mathrm{~kJ} \mathrm{~mol}^{-1}$, respectively (Fig. S16, S18, S20†). The relatively flat shape of the $Q_{\mathrm{st}}$ curves indicates that the binding energy is relatively independent of loading. As mentioned earlier, SIFSIX-2-Cu-i exhibits similar pore size, shape and chemistry to channel A of the DICRO-3-M-ifamily. $Q_{\mathrm{st}}$ values at mid-loading (SIFSIX-2-Cu-i $=35 \mathrm{~kJ} \mathrm{~mol}^{-1}$; DICRO-3-Cu-i $=35 \mathrm{~kJ} \mathrm{~mol}^{-1}$ ) and curve shapes are indeed comparable. $Q_{\mathrm{st}}$ values for DICRO-3M-iare also similar or higher than seen for MOF-5 (34 kJ mol $\left.^{-1}\right),{ }^{21}$ HKUST-1 $\left(35 \mathrm{~kJ} \mathrm{~mol}^{-1}\right),{ }^{22}$ MAF-25 $\left(26 \mathrm{~kJ} \mathrm{~mol}^{-1}\right),{ }^{23}$ InOF-1 $\left(29 \mathrm{~kJ} \mathrm{~mol}^{-1}\right)^{24}$ and NOTT-140 $\left(25 \mathrm{~kJ} \mathrm{~mol}^{-1}\right) .{ }^{25}$ However HUMs with mmo topology exhibit narrower pores and much higher $Q_{\mathrm{st}}$ values at low loading: MOOFOUR-1-Ni $(56 \mathrm{~kJ}$ mol $^{-1}$ ), ${ }^{9 b}$ CROFOUR-1-Ni (50 kJ mol $\left.{ }^{-1}\right)^{9 b}$ and WOFOUR-1-Ni $\left(65 \mathrm{~kJ} \mathrm{~mol}^{-1}\right) \cdot{ }^{9 a}$ Comparison can also be made with DICRO-2$\mathbf{N i - i}$, for which the pore diameter $(3.6 \AA)$ is intermediate to those of channels A and B of DICRO-3-M-i. The $\mathrm{Cr}_{2} \mathrm{O}_{7}{ }^{2-}$ pillar is directed away from the accessible channel in DICRO-2-Niibut towards the interior of the channel in DICRO-3-M-i. The larger $Q_{\text {st }}$ values of DICRO-3-M-i vs. DICRO-2-Ni-i $(30.5 \mathrm{~kJ}$ $\left.\mathrm{mol}^{-1}\right)^{6 a}$ support the importance of pore size and pore chemistry seen for the MFSIX platform. ${ }^{7 b}$ While interpenetration necessarily reduces pore dimensions, likely enhancing binding interactions between sorbate and sorbent, interpenetration may also afford non-uniform pores and significantly change pore structure. Whereas uniform pore binding is likely to be generally preferred for enhanced selectivity, different sorbates could require very different pore structures to optimise the energetics of binding. Therefore, generalisation about the influence of interpenetration upon separations is inappropriate since interpenetrated networks may in some circumstances be more able to create uniform pores than their non-interpenetrated analogues. 
Table 2 Summary of gas sorption data for the DICRO-3-M-i family

\begin{tabular}{|c|c|c|c|c|c|c|c|c|c|}
\hline & $\begin{array}{l}\text { Calculated } \\
\text { void space }^{a}\end{array}$ & $\begin{array}{l}\text { Calculated } \\
\text { micropore } \\
\text { volume }\left(\mathrm{cm}^{3} \mathrm{~g}^{-1}\right)\end{array}$ & $\begin{array}{l}\mathrm{CO}_{2} / \mathrm{N}_{2} \\
\text { selectivity } \\
\text { at }^{b} 293 \mathrm{~K}\end{array}$ & \multicolumn{3}{|l|}{$\mathrm{CO}_{2}$} & \multicolumn{3}{|l|}{$\mathrm{N}_{2}$} \\
\hline DICRO-3-Co-i & $28.2 \%$ & 0.201 & 70.2 & 0.054 & 35 & $8.58 / 25.20$ & 0.052 & 142 & 1.01 \\
\hline DICRO-3-Ni-i & $22.6 \%$ & 0.158 & 79.3 & 0.109 & 37 & $18.59 / 49.76$ & 0.143 & 388 & 1.95 \\
\hline
\end{tabular}

${ }^{a}$ The accessible void space and micropore volume were calculated with the program PLATON using a probe radius of $1.2 \AA .{ }^{b}$ Preliminary selectivity values were calculated as a ratio of gas uptakes at a specified pressure and $293 \mathrm{~K}$ from single component $\mathrm{N}_{2}$ and $\mathrm{CO}_{2}$ data. Langmuir curves were fitted to $\mathrm{CO}_{2}$ isotherms and used to calculate uptake at pressure of $0.85 \mathrm{bar}$, linear curves were fitted to $\mathrm{N}_{2}$ data and uptake calculated at 0.15 bar. ${ }^{c}$ (DR method) $\left[\mathrm{cm}^{3} \mathrm{~g}^{-1}\right]{ }^{d}$ (t-Plot) exp. $\left[\mathrm{cm}^{3} \mathrm{~g}^{-1}\right]$.

\section{Molecular simulations}

Molecular simulations of $\mathrm{CO}_{2}$ adsorption for DICRO-3-Ni-i and DICRO-3-Cu-i indicate that guest $\mathrm{CO}_{2}$ molecules are adsorbed into both channels $\mathrm{A}$ and $\mathrm{B}$ and that, at $\mathrm{CO}_{2}$ saturation, $\mathrm{CO}_{2}$ molecules interact with exposed oxygen atoms of the $\mathrm{Cr}_{2} \mathrm{O}_{7}{ }^{2-}$ pillar (Fig. 4). The tight fit within the channels and the presence of exposed oxygen atoms from $\mathrm{Cr}_{2} \mathrm{O}_{7}{ }^{2-}$ pillars, contributes to the relatively high zero loading $\mathrm{CO}_{2} Q_{\text {st }}$ for these HUMs. Simulations of $\mathrm{CO}_{2}$ adsorption at 273, 283 and $293 \mathrm{~K}$ were performed for DICRO-3-Ni-i and DICRO-3-Cu-i. For DICRO-3-Nii isotherms are in good agreement with the experimental data (Fig. S21 $\dagger$ ). However, for DICRO-3-Cu-i simulated $\mathrm{CO}_{2}$ isotherms correspond well with experimental data only in the low and high-pressure regions of the isotherms for the three temperatures, i.e., before and after the inflection point in the experimental isotherms (Fig. S22 $\dagger$ ). The simulated $Q_{\text {st }}$ values are also in good agreement with experiment at 32.8 (vs. 37) and 33.5 $\mathrm{kJ} \mathrm{mol}^{-1}$ (vs. 37) for DICRO-3-Ni-i and DICRO-3-Cu-i, respectively (Fig. S23, S24 $\dagger$ ). The simulations for DICRO-3-Cu-i do not show the inflection point from the experimental $\mathrm{CO}_{2}$ isotherms because the HUM is treated as a rigid network in the

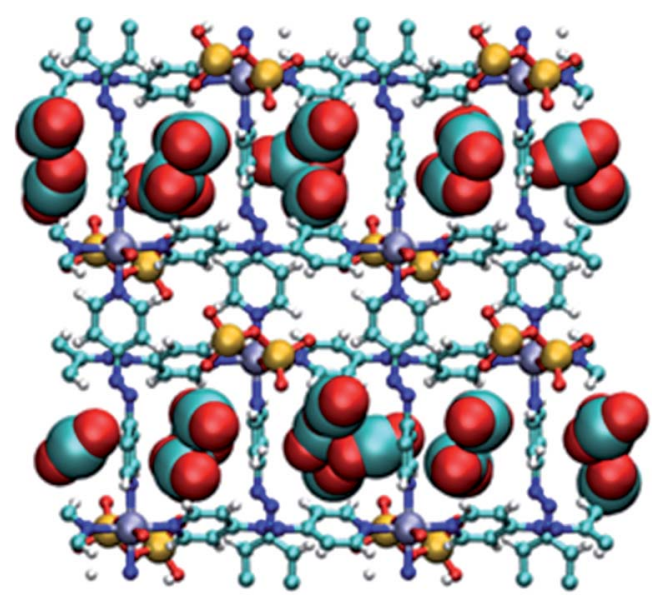

Fig. 4 Simulated packing of $\mathrm{CO}_{2}$ guest molecules in DICRO-3-M-i. View down a-axis. Light blue (carbon), red (oxygen), blue (nitrogen), yellow (chromium), purple $\left(\mathrm{M}^{2+}\right)$, white (hydrogen). simulations. The simulations indicate that the X-ray crystal structure for DICRO-3-Cu-i is representative of the structure occurring after the step (at higher pressure) in the experimental isotherms.

\section{Accelerated stability and temperature programmed desorption}

Because of its relatively high $\mathrm{CO}_{2}$ uptake and $Q_{\text {st }}$, DICRO-3-Ni-i was selected for testing regarding its stability and ability to uptake $\mathrm{CO}_{2}$ directly from the atmosphere, as well as under simulated flue gas conditions. The stability of DICRO-3-Ni-i to atmospheric water vapour was evaluated via accelerated stability testing, ${ }^{\boldsymbol{b} \boldsymbol{b}}$ which simulates long-term storage and shelflife (see ESI for full details and Fig S27-S29†). The surface area of DICRO-3-Ni-i was found to decrease upon increased exposure. An as-synthesised sample exhibited a BET surface area of $388 \mathrm{~m}^{2} \mathrm{~g}^{-1}$, while surface areas for 1 day, 7 days and 16 days were $289 \mathrm{~m}^{2} \mathrm{~g}^{-1}(-25 \%), 255 \mathrm{~m}^{2} \mathrm{~g}^{-1}(-34 \%)$ and $173 \mathrm{~m}^{2} \mathrm{~g}^{-1}$ $(-55 \%)$, respectively. The stability of DICRO-3-Ni-i is comparable to HKUST-1 ( $-28 \%$ surface area following 1 day exposure; $-33 \%$ after 7 days) but superior to Mg-MOF-74 (-74\% surface area following 1 day exposure). ${ }^{6 \boldsymbol{b}}$ The performance of DICRO-3Ni-i for capturing $\mathrm{CO}_{2}$ directly from air and under conditions resembling flue gas streams was also evaluated. TGA/MS was used to determine quantitative uptakes of specific adsorbents from these gas streams (full details given in ESI). DAC measurements on DICRO-3-Ni-i revealed a $\mathrm{CO}_{2}$ uptake of $\sim 0.97$ $\mathrm{L} \mathrm{CO}_{2}$ per $\mathrm{kg}\left(\sim 2 \mathrm{mg} \mathrm{CO}_{2}\right.$ per $\mathrm{g}$ solid $)$ when exposed to the laboratory atmosphere for $12 \mathrm{~h}$ (see Fig. S30† for schematic diagram of DAC/TPD apparatus; all TPD and uptake plots are located in Fig. S32-S40 and data tabulated in Table S9†). This equates to a $S_{\mathrm{CW}} \mathrm{CO}_{2}: \mathrm{H}_{2} \mathrm{O}$ ratio of $>2 \%:<97 \%$ in terms of mass uptake for each component, which is above that measured for HKUST-1 (1\%: $99 \%$ ) but lower than that of SIFSIX-3-Ni (8\% : 92\%) and Mg-MOF-74 (4\% : 96\%). ${ }^{6 \boldsymbol{b}}$ Under simulated flue gas conditions (moist $\mathrm{CO}_{2}, 0.15$ atm), DICRO-3-Ni-i exhibits high uptake of $\mathrm{CO}_{2}, \sim 9.77 \mathrm{~L} \mathrm{CO}_{2}$ per $\mathrm{kg}\left(19.2 \mathrm{mg} \mathrm{CO}_{2}\right.$ per $\mathrm{g}$ solid) (Fig. 5). This equates to a $S_{\mathrm{CW}} \mathrm{CO}_{2}: \mathrm{H}_{2} \mathrm{O}$ ratio of 53\% : 47\% which is higher than that of HKUST-1 (8.5\% : >91\%); slightly higher than to that of Mg-MOF-74 (51\%:49\%) and second only to SIFSIX-3-Ni (62\% : 38\%) when tested under the 


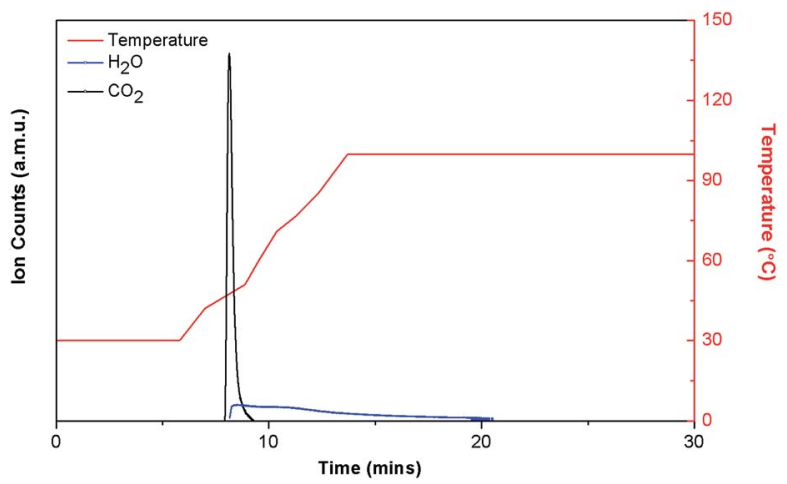

Fig. 5 TPD plot for DICRO-3-Ni-i exposed to moist 0.15 atm $\mathrm{CO}_{2}$. Uptake equal to $19.2 \mathrm{mg} \mathrm{CO} 2$ per g, 52.7\% $\mathrm{CO}_{2}, \sim 47.3 \% \mathrm{H}_{2} \mathrm{O}$.

same conditions. ${ }^{6 \boldsymbol{b}}$ TPD experiments revealed that desorption occurs below $50{ }^{\circ} \mathrm{C}$ for DICRO-3-Ni-i, which is relatively easier than both HKUST-1 and Mg-MOF-74.

\section{Conclusions}

A family of 3D Hybrid Ultramicroporous Materials (HUMs), DICRO-3-M-i, with four members has been synthesised using a crystal engineering approach that exploits $\mathrm{Cr}_{2} \mathrm{O}_{7}{ }^{2-}$ anions to pillar square lattice networks (sql) constructed from 4,4'-azopyridine organic linkers (3) and $\mathbf{M}^{2+}$ metal centres. Single component gas sorption measurements for three of these compounds, DICRO-3-Co-i, DICRO-3-Ni-i and DICRO-3-Cu-i, were collected and reveal permanent microporosity, selective $\mathrm{CO}_{2} / \mathrm{N}_{2}$ uptake and relatively high $Q_{\mathrm{st}}$ values towards $\mathrm{CO}_{2}$. Temperature programmed desorption experiments conducted on DICRO-3-Ni-i revealed excellent $\mathrm{CO}_{2}$ uptake and $S_{\mathrm{CN}}$ when exposed to flue gas conditions. Structural analysis, gas sorption experiments and molecular simulations from this study reaffirm that HUMs can afford favourable sorbate-sorbent interactions. Specifically, for the DICRO-3-M-i family, $\mathrm{Cr}_{2} \mathrm{O}_{7}{ }^{2-}$ anions orient in such a manner that terminal O-atoms line the walls of the accessible 1D ultramicroporous channels, resulting in high $Q_{\text {st }}$ and enhanced $\mathrm{CO}_{2}$ sorption performance.

To conclude, whereas we have not yet elucidated the origin of the flexibility in this family of materials, there are four takehome messages that could aid the custom-design of porous materials with enhanced gas sorption performance: the combination of ultramicropores and strong electrostatics in HUMs necessarily leads to tight binding sites for polarisable guests such as $\mathrm{CO}_{2}$; interpenetration can be used to facilitate ultramicropores, but may also generate non-uniform pores; the presence of groups with strong electrostatics alone is not sufficient, but rather these groups must be favourably positioned to achieve optimal guest binding; binding energies of 35-40 kJ mol${ }^{-1}$ enable facile regeneration of these sorbents.

\section{Acknowledgements}

This publication emanates from research conducted with financial support from the Science Foundation Ireland under the International Strategic Cooperation Award Grant Number SFI/13/ISCA/2845. Additionally, M. J. Z. acknowledges Science Foundation Ireland for support (SFI Award 13/RP/B2549). B. S. acknowledges the (Award No. CHE-1152362). Computational resources were made available by XSEDE Grant No. TGDMR090028. The use of the services provided by Research Computing at the University of South Florida is also acknowledged.

\section{Notes and references}

1 (a) G. R. Desiraju, The Design of Organic Solids, Elsevier, Amsterdam, 1989; (b) B. Moulton and M. J. Zaworotko, Chem. Rev., 2001, 101, 1629.

2 (a) A. F. Wells, Three Dimensional Nets and Polyhedra, Wiley, New York, 1977; (b) B. F. Hoskins and R. Robson, J. Am. Chem. Soc., 1990, 112, 1546; (c) B. F. Hoskins and R. Robson, J. Am. Chem. Soc., 1989, 111, 5962.

3 J. J. Perry IV, J. A. Perman and M. J. Zaworotko, Chem. Soc. Rev., 2009, 38, 1400.

4 (a) S. R. Batten, S. M. Neville and D. R. Turner, Coordination Polymers Design, Analysis and Application Introduction, RSC Publishing, Cambridge, UK, 2009; (b) S. Kitagawa, R. Kitaura and S. Noro, Angew. Chem., Int. Ed., 2004, 43, 2334; (c) S. R. Batten and R. Robson, Angew. Chem., Int. Ed., 1998, 37, 1460.

5 (a) Metal-Organic Frameworks: Applications from Catalysis to Gas Storage, ed. D. Farrusseng, Wiley-VCH Verlag GmbH \& Co, Weinheim, 2011; (b) Metal-Organic Frameworks: Design and Application, ed. L. R. MacGillivray, John Wiley \& Sons, Hoboken, USA, 2010; (c) Functional Metal-Organic Frameworks: Gas storage, separation and catalysis, ed. M. Schröder, Springer-Verlag, Berlin, 2009.

6 (a) H. S. Scott, A. Bajpai, K. J. Chen, T. Pham, B. Space, J. J. Perry IV and M. J. Zaworotko, Chem. Commun., 2015, 51, 14832; (b) A. Kumar, D. G. Madden, M. Lusi, K. J. Chen, E. A. Daniels, T. Curtin, J. J. Perry IV and M. J. Zaworotko, Angew. Chem., Int. Ed., 2015, 54, 14372.

7 (a) S. K. Elsaidi, M. H. Mohamed, H. T. Schaef, A. Kumar, M. Lusi, T. Pham, K. A. Forrest, B. Space, W. Xu, G. J. Halder, J. Liu, M. J. Zaworotko and P. K. Thallapally, Chem. Commun., 2015, 51, 15530; (b) P. Nugent, Y. Belmabkhout, S. D. Burd, A. J. Cairns, R. Luebke, K. Forrest, T. Pham, S. Q. Ma, B. Space, L. Wojtas, M. Eddaoudi and M. J. Zaworotko, Nature, 2013, 495, 80; (c) O. Shekhah, Y. Belmabkhout, K. Adil, P. M. Bhatt, A. J. Cairns and M. Eddaoudi, Chem. Commun., 2015, 51, 13595; (d) O. Shekhah, Y. Belmabkhout, Z. J. Chen, V. Guillerm, A. Cairns, K. Adil and M. Eddaoudi, Nat. Commun., 2014, 5, 1.

8 (a) S. D. Burd, S. Q. Ma, J. A. Perman, B. J. Sikora, R. Q. Snurr, P. K. Thallapally, J. Tian, L. Wojtas and M. J. Zaworotko, J. Am. Chem. Soc., 2012, 134, 3663; (b) S. Noro, S. Kitagawa, M. Kondo and K. Seki, Angew. Chem., Int. Ed., 2000, 39, 2082; (c) P. Nugent, V. Rhodus, T. Pham, B. Tudor, K. Forrest, L. Wojtas, B. Space and M. Zaworotko, Chem. Commun., 2013, 49, 1606. 
9 (a) M. H. Mohamed, S. K. Elsaidi, T. Pham, K. A. Forrest, B. Tudor, L. Wojtas, B. Space and M. J. Zaworotko, Chem. Commun., 2013, 49, 9809; (b) M. H. Mohamed, S. K. Elsaidi, L. Wojtas, T. Pham, K. A. Forrest, B. Tudor, B. Space and M. J. Zaworotko, J. Am. Chem. Soc., 2012, 134, 19556.

10 N. L. Rosi, M. Eddaoudi, J. Kim, M. O'Keeffe and O. M. Yaghi, Angew. Chem., Int. Ed., 2002, 41, 284.

11 X. Y. Chen, B. Zhao, P. Cheng, B. Ding, D. Z. Liao, S. P. Yan and Z. H. Zhiang, Eur. J. Inorg. Chem., 2004, 562.

12 Y. Hayashi, T. Tagami, H. Mano and A. Uehara, Chem. Lett., 2001, 30, 562.

13 A. L. Kopf, P. A. Maggard, C. L. Stern and K. R. Poeppelmeier, Acta Crystallogr., Sect. C: Cryst. Struct. Commun., 2005, 61, M165.

14 Topology determined using the computer program TOPOS: V. A. Blatov, A. P. Shevchenko and D. M. Proserpio, Cryst. Growth Des., 2014, 14, 3576.

15 F. H. Allen, Acta Crystallogr., Sect. B: Struct. Sci., 2002, 58, 380.

16 A. L. Spek, J. Appl. Crystallogr., 2003, 36, 7.

17 (a) K. L. Mulfort, O. K. Farha, C. D. Malliakas, M. G. Kanatzidis and J. T. Hupp, Chem.-Eur. J., 2010, 16, 276; (b) S. Kitagawa and K. Uemura, Chem. Soc. Rev., 2005, 34, 109.
18 T. Devic, P. Horcajada, C. Serre, F. Salles, G. Maurin, B. Moulin, D. Heurtaux, G. Clet, A. Vimont, J. M. Greneche, B. Le Ouay, F. Moreau, E. Magnier, Y. Filinchuk, J. Marrot, J. C. Lavalley, M. Daturi and G. Ferey, J. Am. Chem. Soc., 2010, 132, 1127.

19 (a) B. Arstad, H. Fjellvag, K. O. Kongshaug, O. Swang and R. Blom, Adsorption, 2008, 14, 755; (b) K. J. Chen, R. B. Lin, P. Q. Liao, C. T. He, J. B. Lin, W. Xue, Y. B. Zhang, J. P. Zhang and X. M. Chen, Cryst. Growth Des., 2013, 13, 2118; (c) R. Vaidhyanathan, S. S. Iremonger, K. W. Dawson and G. K. H. Shimizu, Chem. Commun., 2009, 45, 5230.

20 F. Rouquerol, J. Rouquerol, K. S. W. Sing, P. Lllewellyn and G. Maurin, Adsorption by Powders and Porous Solids: Principles, Methodology and Applications, Academic Press, Amsterdam, 2nd edn, 2014.

21 Z. X. Zhao, Z. Li and Y. S. Lin, Ind. Eng. Chem. Res., 2009, 48, 10015.

22 Q. Y. Yang, C. Y. Xue, C. L. Zhong and J. F. Chen, AIChE J., 2007, 53, 2832.

23 J. B. Lin, J. P. Zhang and X. M. Chen, J. Am. Chem. Soc., 2010, 132, 6654.

24 J. J. Qian, F. L. Jiang, D. Q. Yuan, M. Y. Wu, S. Q. Zhang, L. J. Zhang and M. C. Hong, Chem. Commun., 2012, 48, 9696.

25 C. R. Tan, S. H. Yang, N. R. Champness, X. A. Lin, A. J. Blake, W. Lewis and M. Schröder, Chem. Commun., 2011, 47, 4487. 